\title{
Nillismo e política em Leo Strauss
}

\author{
Evaldo Sampaio ${ }^{1}$
}

RESUMO: Trata-se de pensar a possibilidade da filosofia política. Para tanto, procura-se situar a questão a partir da obra de Leo Strauss, objetivando-se mostrar por que o niilismo contemporâneo - em suas mais difundidas e às vezes insuspeitas manifestações - impede a realização e mesmo a existência de uma reflexão sobre a natureza das coisas políticas. Tendo-se a retomada por parte de Strauss do "direito natural" como chave de leitura tanto para o "problema central da filosofia política" quanto para o enfrentamento de seus principais opositores, espera-se investigar o sentido e a plausibilidade das críticas aos motivos que nos conduzem ao niilismo e, caso estas se mostrem apropriadas, apontar como um proposto "renascimento do racionalismo político clássico" pode reconduzir à interrogação filosófica acerca do que é bom, da boa vida, da melhor sociedade, de "como deve o homem viver".

PALAVRAS-CHAVE: Direito natural. Niilismo. L. Strauss.

\section{Cabe a um leitor atento questionar:}

Quem foi Leo Strauss? Mais precisamente: o que ele pretendia? Que filosofia política professava? Ou deveríamos fazer uma pergunta ainda mais básica: o que ele entendia por filosofia política? Entre 1943 e 1970, Strauss se apoderou de uma moribunda disciplina acadêmica denominada "história das ideias políticas" e a transformou numa investigação de amplo significado e vitalidade. Como a história do pensamento político adquiriu em suas mãos tal vigor? O que há em seus escritos que continua a contrariar respeitadas concepções e procedimentos intelectuais e, desse modo, despertar tanto fascinação quanto ódio? ${ }^{2}$

Revisitar o pensamento de Leo Strauss talvez já estivesse plenamente justificado caso se buscasse tão somente responder a essas perguntas quanto a um

\footnotetext{
${ }^{1}$ Professor Adjunto do Departamento de Filosofia da Universidade de Brasília.

${ }^{2}$ Thomas L. Pangle, em sua introdução à seleção de artigos de Leo Strauss, The Rebirth of Classical Political Philosophy, p. 1.
} 
autor de decisiva importância na filosofia política contemporânea ${ }^{3}$ e de recepção crítica ainda não consolidada, no Brasil $1^{4}$. No entanto, o que conduz aqui à reflexão é uma perplexidade para além do mero interesse histórico ou bibliográfico, pois diz respeito à própria natureza das coisas políticas. Pretende-se, em consonância com Strauss, interrogar a possibilidade mesma da filosofia política.

Toda ação política, argumenta Strauss, busca conservar ou mudar um determinado estado de coisas. Como aqueles que querem preservar esperam evitar uma mudança para o pior e os que querem mudar visam obter o melhor, "toda ação política é guiada por uma ideia de melhor ou pior". Tal ideia pressupõe uma ou mais ideias acerca do bem, sendo que estas nos aparecem como opiniões sobre o bem ${ }^{5}$. Como há diferentes opiniões sobre o bem, aqueles que desejam preservar ou mudar um estado de coisas se veem impelidos a tentar substituir esta ou aquela opinião a propósito do bem por um conbecimento do bem, porque, como as opiniões expressam "erros, palpites, crenças, prejuízos, previsões, etc." ${ }^{\prime \prime}$ sobre as coisas políticas, guiar-se apenas por elas pode nos levar a evitar o melhor ou mudar para o pior. Logo, a finalidade da filosofia política consiste em superar as meras opiniões sobre o bem e tentar alcançar um conhecimento sobre o que é bom, da boa vida, da melhor sociedade, porquanto "a boa sociedade é o bem político por excelência". Se a toda ação política subjaz uma ideia de melhor ou pior, as coisas políticas não podem ser tratadas com neutralidade, de modo que não se as entende "caso não se leve a sério sua implícita ou explícita requisição de serem julgadas em termos de bondade ou maldade, de justiça ou injustiça". Para tanto, a filosofia não investiga esta ou aquela situação política e sim as coisas políticas

\footnotetext{
${ }^{3}$ Como destaca Steven B. Smith, "Leo Strauss (1899-1973) was a central figure in the revival of the study of political philosophy. He was highly controversial during his lifetime, and the debates over his ideas and his legacy have only deepened in the years after his death. His writings attracted passionate defenders and equally passionate critics. His name itself has become an 'ism': Straussianism" [cf. "Leo Strauss Today", p. 1]. Para um maior esclarecimento - que, paradoxalmente, consiste necessariamente num reforço das ambiguidades quanto a "o que é um straussiano" -, ver o primeiro capítulo de Anne Norton, em seu Leo Strauss and the Politics of the American Empire, e o "Straussians", de Michael Zuckert.

${ }^{4}$ Além de não contarmos (até onde se conseguiu aqui averiguar) com nenhum livro de recepção brasileira dedicado exclusiva ou preponderantemente a Leo Strauss, a primeira tradução de uma de suas obras para o português foi editada somente em 2009 [Direito Natural e História, tradução lusitana de Miguel Morgado]. Acrescente-se que, de acordo com o "banco de teses" da CAPES [disponível em: http:/ /www.capes.gov.br/servicos/banco-de-teses; acesso em: 01 mai. 2010], até 2009 não há registro de nenhum trabalho de pós-graduação concluído dedicado ao pensamento do filósofo.
}

${ }^{5}$ STRAUSS, L. What is Political Philosophy?, p. 10.

${ }^{6}$ Ibidem, p. 15.

${ }^{7}$ Ibidem, p. 10.

${ }^{8}$ Ibidem, p. 12 
em sua totalidade. Logo, interessa-se precisamente pela substituição das opiniões sobre as coisas políticas em sua totalidade pelo conhecimento das coisas políticas em sua totalidade. Por isso, os primeiros filósofos políticos surgiram em Atenas quando se passou a refletir diretamente sobre a sociedade boa e justa entendida como intrinsecamente relacionada à melhor maneira de viver. Caso disponha de tal conhecimento, o filósofo político pode então julgar o que é o melhor e o que é o pior. Mesmo que tal conhecimento não possa ser obtido satisfatoriamente, como "a filosofia não é essencialmente a posse da verdade, mas a busca pela verdade", a filosofia política retém sua relevância por trazer à tona e refletir sobre tais questões fundamentais.

Já que a filosofia política é a tentativa de substituir opiniões sobre a "vida boa" e a "melhor sociedade" pelo conhecimento da melhor maneira de viver e da boa ordenação política, é preciso, com Strauss, distingui-la do pensamento político em geral (o qual envolve todo e qualquer pensamento sobre a política, a despeito de ser opinião ou conhecimento); da teoria política (cujo propósito de determinar condutas para solucionar uma situação política específica a separa da procura pelo conhecimento das coisas políticas, em sua totalidade); da teologia política (por seu ensinamento fundamentado na revelação divina); da filosofia social (que, embora compartilhe o mesmo objeto da filosofia política, afasta-se desta, por pressupor "a associação política como parte de algo maior cujo todo se designa pelo termo "sociedade"'); e, especialmente, da ciência política moderna (por motivos que serão esclarecidos adiante $)^{10}$. Não obstante cultivada ininterruptamente desde Sócrates, parece a Strauss que "a filosofia do que é próprio ao homem" se encontra em nossos dias num tal "estado de decadência ou degeneração" que não seria um exagero dizer que "hoje a filosofia política não mais existe"

Um primeiro motivo para tanto é a mudança quanto ao próprio caráter da sociedade. Antes, os homens inteligentes adquiriam um entendimento dos assuntos relevantes para a cidade pela escuta dos mais sábios e experientes, pela leitura dos bons historiadores ou simplesmente pela observação atenta das questões públicas. Nas "sociedades de massa" consolidadas desde o século XIX e caracterizadas pela complexidade e transformação ininterrupta, o acesso ao conhecimento das questões políticas exige uma dedicação exclusiva e especializada que acabou por segmentar a investigação em várias disciplinas com objetos e métodos distintos como a economia, a sociologia ou a psicologia social ${ }^{12}$. Assim

\footnotetext{
9 Ibidem, p. 11.

10 Ibidem, p. 12-13.

11 Ibidem, p. 17.

12 Ibidem, p. 15.
} 
diluída, não surpreende que se torne um problema compreender adequadamente o modo de tratamento dos assuntos humanos que caracteriza a filosofia política. Em segundo lugar, a dúvida quanto a sua possibilidade já se encontra na própria filosofia política. Afinal, se aquilo que um general ou um médico procuram, a saber, a vitória e a saúde, não são controversos, por sua vez, aquilo que o filósofo político pretende pensar, o "bem comum", é "essencialmente controverso". Disso se segue que tal indeterminação quanto ao seu objetivo é coeva à própria compreensão da investigação filosófica acerca das coisas políticas, lançando suspeitas quanto a sua pertinência ${ }^{13}$ - afinal, como se dispor a um exame sério de algo cujo propósito é obscuro, quiçá indeterminado? Em terceiro lugar, a possibilidade da filosofia política é atualmente posta em questão sobretudo por muitos considerarem que sua única importância é como uma relíquia para a pesquisa histórica e que, conquanto fosse originalmente identificada com a ciência política, agora é tida como "não-científica" e "a-histórica"14. "Ciência" e "História", "as duas grandes forças do mundo moderno", são, na conjuntura preparada por Strauss, os maiores obstáculos para a possibilidade da filosofia política. Por caminhos diferentes, porém complementares, a ciência e a "consciência histórica" rejeitam toda e qualquer possibilidade de uma norma ou escolha filosófica dos valores e, por conseguinte, negam um conhecimento racional do que é melhor ou pior, da boa vida e da melhor sociedade ${ }^{15}$. Dito diretamente: a incapacidade de qualquer avaliação legítima ou filosófica dos valores, i.e., o niilismo, é o que conduz à crença na impossibilidade da filosofia política ${ }^{16}$.

Uma das principais conjecturas de Strauss é que o desenvolvimento do niilismo moderno se deve ao declínio da noção de direito natural. Como o direito natural é um dos temas clássicos - ou talvez o tema clássico - da filosofia política, entrelaçar o seu destino ao do niilismo permite tanto explicar o desaparecimento da filosofia política quanto justificar a posição incomparável desta em relação à crise da modernidade ${ }^{17}$. No prefácio de Direito Natural e História, Strauss faz ver que "a ciência social americana adotou a mesma atitude em relação ao direito

\footnotetext{
${ }^{13}$ Ibidem, p. 16.

14 Ibidem, p. 17-18.

15 Ibidem, p. 18.

16 O título deste artigo é inspirado na coletânea de textos de Strauss organizada e traduzida para o francês por Olivier Sedeyn, Nibilisme et Politique, na qual consta o primeiro ensaio em que Strauss aborda em detalhe a questão do niilismo, a saber, Sur Le Nihilisme Allemand [On German Nihilism]. Um estudo acerca dessa formulação inicial da questão do niilismo e parte de seu desenvolvimento posterior, na filosofia de Strauss, foi realizado por Joel Kraemer em seu “To Spare the Vanquished and Crush the Arrogant': Leo Strauss's Lecture on "German Nihilism".
}

${ }^{17}$ STRAUSS, L. The City and the Man, prefácio. 
natural que, há uma geração atrás e com alguma plausibilidade, ainda podia ser descrita como característica do pensamento alemão", no caso, que não há nenhum direito natural. Tal adoção tanto contrariava os princípios da Declaração de Independência dos Estados Unidos, segundo os quais era autoevidente "a fundação natural e divina dos direitos do homem”, quanto indicava que ali, mais uma vez, "uma nação, derrotada no campo de batalha, e, por assim dizer, aniquilada enquanto ser político, privava os seus conquistadores do fruto mais sublime da vitória ao impor-lhes o jugo do seu próprio pensamento"18. O contraste assim estabelecido pelo então recém-contratado professor alemão de "história das ideias políticas" quando da primeira série de conferências de seu magistério no Curso de Ciência Política da Universidade de Chicago visava trazer à tona, para uma audiência talvez ainda disponível a ouvi-lo, o que já se tornara inaudível àqueles para os quais os próprios termos "direito natural" e "humanidade" soavam como que ininteligíveis. O holocausto contíguo a uma ciência social incapaz de avaliar o exercício justo do poder para além das legislações e tribunais dos diversos países - ou seja, para além de um direito positivo - era indicado como um risco para os "vencedores", pois estes, ao abandonarem algumas das "evidências" que contribuíram para lhes tornar "a mais poderosa e próspera das nações da Terra", agora se encontravam diante de um risco similar aos dos vencidos ${ }^{19}$. A despeito da estratégia retórica para despertar o interesse de um auditório particular, Strauss pretende aqui anunciar um problema mais amplo e sinuoso: a rejeição por parte da ciência social a qualquer exercício legítimo do poder que não oriundo do direito positivo equivale, se bem compreendido, à própria impossibilidade de reflexão acerca da fundamentação do poder político. Daí que Strauss desenvolva tal perquirição não pela ciência política - que, segundo lhe parece, vetava em princípio tal empreita - e sim pela filosofia política - entendida como "ciência política clássica".

O que Strauss pretendia, bem como o que entendia e professava como filosofia política, exige explicitar como ele, após identificar os principais impedimentos não por acaso modernos quanto à possibilidade da filosofia política, objetivava, pela crítica de seus exemplos mais representativos, mostrar a improcedência desses entraves e promover o que se pode caracterizar como

\footnotetext{
18 STRAUSS, L. Direito Natural e História, p. 4.

19 Ibidem, p. 5. Após sua chegada aos Estados Unidos, Leo Strauss lecionou por uma década na New School of Social Research, instituição que abrigou vários professores exilados quando da II Guerra Mundial, como, e.g., Hanna Arendt. Em 1949, Strauss assume uma cátedra na Universidade de Chicago e as suas primeiras preleções foram editadas posteriormente sob o título Direito Natural e História.
} 
um "renascimento do racionalismo político clássico"20. Dentre as várias tópicas e operadores conceptuais que utiliza para tanto, destaca-se a mencionada discussão a respeito do direito natural, fio condutor privilegiado para a compreensão não somente do niilismo da ciência social mas também da abordagem histórica contemporânea. A partir do exame das réplicas de Strauss às objeções "científicas" e "historicistas" ao direito natural, oportunamente identificado com o problema fundamental da filosofia política, espero restituir o debate quanto à possibilidade desta e assim justificar a busca por sua realização plena. Contudo, de que modo a ciência e a atual abordagem histórica são niilistas? Como a retomada do direito natural pode ser um caminho para decifrar e, quem sabe, solucionar o problema central da filosofia política?

Para tentar conhecer a natureza e a melhor ordenação das coisas políticas, a filosofia se ocupa não de uma dada situação, mas da vida política ou do humano enquanto tal. Daí que apenas quando o "aqui e o agora" deixam de ser o centro de referência da investigação é que se inicia a abordagem filosófica ${ }^{21}$. Isso obviamente não significa um desinteresse pelas circunstâncias políticas efetivas, porém, que a maneira pela qual o filósofo as indaga é guiada por aquilo que supostamente está para além deste ou daquele momento. O filósofo não está preocupado em determinar qual a melhor ordenação política de que atualmente dispomos ou de que já dispusemos e sim a melhor ordenação que pode existir, a despeito de que sua atualização apenas possa ocorrer em condições extraordinárias. É nessa acepção estrita que a filosofia política clássica se pode dizer "idealista". Em contraponto àqueles que identificam o bem com o prazer, as "doutrinas clássicas" julgam que o bem é essencialmente diferente e mais fundamental do que o prazer. O motivo é que "o fato primordial não é o prazer ou a inclinação pelo prazer, mas antes as necessidades e o esforço por satisfazê-las"; logo, é a existência de diversas necessidades o que explica a variedade dos prazeres. Como seres dessemelhantes procuram ou experimentam prazeres dessemelhantes ("os prazeres de um asno são diferentes dos de um ser humano"), parece que estes remontam a necessidades também díspares, as quais, por serem mais ou menos comuns aos que pertencem a uma mesma espécie, sugerem que talvez exista "uma ordem natural das necessidades". Se for assim, então "a ordem das necessidades de um ser remete a sua constituição natural" e "é essa constituição que determina a ordem e a hierarquia das diversas inclinações de um ser". A pergunta da filosofia política pelo que é bom, pela boa vida e a melhor sociedade consiste, em última análise, na tentativa de estabelecer "o que é a natureza do homem ou a constituição natural do homem" para determinar "o que é por natureza bom para o homem

\footnotetext{
${ }^{20}$ Esta adequada caracterização foi cunhada por Thomas L. Pangle, op. cit.

${ }^{21}$ STRAUSS, L. What is Political Philosophy?, p. 16.
} 
ou o que é o bem humano em geral"22. O problema da possibilidade mesma da filosofia política remete assim ao direito natural e, segundo Strauss, especialmente ao direito natural clássico ${ }^{23}$. Se houver um direito natural discernível pela razão, há filosofia política; caso contrário, há apenas, quem sabe, ciência, teologia, teoria, e/ou pensamento político.

Para justificar que essa consanguinidade não é arbitrária, Strauss nos remete à origem da ideia de direito natural. Segundo lhe parece, "compreender o problema do direito natural requer partir não da compreensão cientifica das coisas políticas, mas da sua compreensão natural, i.e., do modo como elas se apresentam na vida política, na ação cotidiana que nos diz respeito, quando temos de tomar decisões"24. Por isso, a maior importância que Strauss concede ao direito natural clássico e, por conseguinte, à filosofia política clássica, em relação ao direito natural moderno, uma vez que aquela parece "caracterizada pelo fato de se relacionar diretamente com a vida política". Afinal, "apenas depois que os filósofos clássicos fizeram seu trabalho é que a filosofia política se tornou definitivamente "estabelecida", sendo que a filosofia posterior adquire tão-só um contato indireto com a vida política por intermédio da assim constituída tradição da filosofia política. Na prática, isso significa que, em vez de, à semelhança dos filósofos modernos, dar início às suas pesquisas pela contraposição entre "“estado de natureza' e 'estado civil', 'fatos' e 'valores', 'realidade' e 'ideologias', 'o mundo' e 'os mundos das diferentes sociedades', os quais são - ou eram - estranhos à vida política enquanto tal", os filósofos clássicos encontram suas questões "nas discussões das assembleias e conselhos", formulando-as numa terminologia que lhes é "inteligível e familiar"25. Destaque-se que simplesmente "identificar o mundo natural ou pré-científico com o mundo em que vivemos é somente lidar com uma abstração", já que "o mundo em que vivemos é desde logo um produto da ciência ou ao menos profundamente influenciado pela existência da ciência". Para apreender o mundo natural como um mundo que é radicalmente pré-científico e pré-filosófico, "é preciso recuar até antes do nascimento da ciência

\footnotetext{
22 STRAUSS, L. Direito Natural e História, respectivamente, p. 110-111; 82-83; 9.

23 No prefácio à sétima edição americana de Natural Right and History [não incluído na edição portuguesa], redigido em setembro de 1970, Strauss revela: "Nothing that I have learned has shaken my inclination to prefer 'natural right', especially in its classical form, to the reigning relativism, positivism oh historicism. To avoid a common misunderstanding, I should add the remark that the appeal to a higher law, if that is understood in terms of 'our' tradition as distinguished from 'nature', is historicist in character, if not in intention. The case is obviously different if appeal is made to divine law; still, the divine law is not the natural law, let alone natural right".
}

24 STRAUSS, L. Direito Natural e História, p. 71.

${ }^{25}$ STRAUSS, L. On Classical Political Philosophy [n: What is Political Philosophy and others Writings, p. 78-80]. 
e da filosofia". Como fazê-lo? A aposta de Strauss é de que, para tanto, "não é preciso proceder a amplos estudos antropológicos e forçosamente hipotéticos", visto que "a informação fornecida pela filosofia clássica sobre suas origens, sobretudo se esta informação for complementada com a apreciação das premissas mais elementares da Bíblia, é suficiente para reconstituir o caráter essencial do mundo natural ${ }^{26}$. O dito renascimento do racionalismo político clássico visado por Strauss consiste então numa restauração da filosofia ou do direito natural clássico, menos pela chave de leitura da tradição filosófica que deles se originou, do que por suas relações com a vida política e o encoberto mundo natural.

A ideia de direito natural é ignorada enquanto se ignora, como é o caso do Antigo Testamento, a ideia de natureza. Ao se compreender "a filosofia como a procura dos principios de todas as coisas", i.e., "a procura das origens de todas as coisas ou das coisas primeiras", pode-se reencontrar o caminho que conduziu à identificação das coisas primeiras com a natureza e, por conseguinte, fazer ver por que "onde não há filosofia não há conhecimento do direito natural enquanto tal”. Apoiando-se nas informações contidas nos escritos de Heródoto, Platão, Aristóteles, Cícero, dentre outros, Strauss busca reconstituir "a descoberta da natureza" e apontar como "toda a história da filosofia nada mais é senão o registro das tentativas sucessivas de apreender todas as implicações da descoberta crucial que alguns gregos fizeram há 2600 anos ou mais". O equivalente pré-filosófico de "natureza" é o costume ou o modo de viver. Nesse estágio, "não se fazia qualquer divisão fundamental entre costumes e modos que são sempre e em toda parte os mesmos e os que variam de tribo para tribo". Como tanto a frequência quanto a antiguidade pareciam garantir a justeza de um modo de agir e ser, a vida préfilosófica associara então o bom e o ancestral, sendo que o "antigo" e "nosso" era tido como "bom" e o "novo" e "estranho" como "mau". Inclusive, como Platão encena n'As Leis, "é-se levado a crer que os antepassados, ou aqueles que estabeleceram os modos ancestrais, eram deuses ou filhos de deuses ou que pelo menos 'viviam junto com os deuses", de maneira que, submetidas à "autoridade", as possíveis questões relativas ao modo reto eram respondidas antes mesmo de

\footnotetext{
${ }^{26}$ STRAUSS, L. Direito Natural e História, p.70. Esse passo argumentativo parece trazer consigo uma crítica ou mesmo uma radicalização da intuição básica da fenomenologia, porque, como relata Strauss, "Husserl once said to me, who had be trained in the Marburg neo-kantian school, that the neo-kantians were superior to all other German philosophical schools, but they made the mistake of beginning with the roof. He meant the analysis of the science. But science, Husserl taught, is derivative from our primary knowledge of the world of things: science is not the perfection of man's understanding of the world, but a specific modification of that prescientific understanding. The meaningful genesis of science out of prescientific understanding is a problem: the primary theme is the philosophical understanding of the prescientific world, and therefore in the first place the analysis of the sensibly perceived thing" [cf. STRAUSS, L. "An Introduction to Heideggerian Existencialism" [In: The Rebirth of Classical Political Rationalism, p. 28-29].
} 
formuladas. Assim, Strauss assinala que a pergunta mesma por um direito natural pressupõe que se duvide da autoridade. Isso não significa que, tão logo surja, a ideia de direito natural não possa se entrelaçar à crença numa lei divinamente revelada, mas que a predominância dessa crença impeça o nascimento da ideia de direito natural é suficiente para justificar que ambas não estão originalmente relacionadas - como, aliás, fica sugerido pela inexistência do termo hebraico para "natureza", no Antigo Testamento ${ }^{27}$. Revestindo-se essa separação por uma terminologia recorrente no pensamento de Strauss, vê-se aqui também um caso exemplar e original da oposição entre Filosofia e Revelaşão, "Atenas e Jerusalém"28. As dificuldades quanto ao poder da autoridade começam quando se percebe a contradição entre os vários códigos divinos relegados pelos ancestrais e se é levado à dúvida sobre qual deles seria o melhor ou mais correto. Se a antiguidade das normas não mais garante que sejam boas, entende-se como a filosofia advém dessa separação entre o bom e o ancestral, tornando-se uma investigação das coisas primeiras, interpretadas como aquilo que é melhor, superior, anterior ${ }^{29}$.

A procura das coisas primeiras foi, pois, inicialmente orientada pela distinção pré-filosófica (a) entre o que se ouviu dizer e/ou fora visto por outros e aquilo que se viu e/ou ouviu diretamente e (b) pela separação entre as coisas artificiais, que são feitas pelo homem, e as que não são feitas pelo homem. Essa bifurcação conduziu à descoberta da natureza, quando se passou a considerar como inferior aquilo que apenas se ouviu dizer e é produzido pelo homem e como superior aquilo que não foi feito pelo homem e, por isso, poderia ser visto e ouvido diretamente por qualquer um, a qualquer momento. Por conseguinte, a noção de costume ou modo de viver se divide nas concepções de natureza e de convenção. A convenção foi então tida como aquilo que oculta a natureza e que se mostrara tão eficiente nisso que a natureza antes nos aparecia como costume. A filosofia substitui a autoridade do ancestral por algo que é mais antigo ou "anterior" do que qualquer tradição, o que é bom por natureza, reconhecido não simplesmente como a autoridade, mas como o "padrão" de todas as coisas. Conquanto "a descoberta da natureza ou da distinção fundamental entre natureza e convenção é a condição necessária para o aparecimento da ideia de direito natural", certamente não é uma condição suficiente, uma vez que todo o direito

\footnotetext{
27 STRAUSS, L. Direito Natural e História, p. 71-75.

${ }^{28}$ Um estudo da presença e do desenvolvimento do conflito entre Atenas e Jerusalém - ou entre "revelação" e "filosofia" - na obra de Strauss, pode ser encontrado em Susan Orr, Jerusalem and Athens: Reason and Revelation in the Works of Leo Strauss. Para uma análise específica quanto ao surgimento do problema teológico-político em Strauss, ver D. Janssens, Between Jerusalem and Athens: Philosophy, Prophecy and Politics in Leo Strauss's Early Thought.
}

${ }^{29}$ STRAUSS, L. Direito Natural e História, p. 76-78. 
poderia ser convencional. Por isso, "o tema primordial da controvérsia política" é saber se há ou não direito natural ${ }^{30}$. Para Strauss, o problema apenas pode ser resolvido de maneira apropriada se (i) encontrarmos um padrão que nos permita desvencilhar as necessidades genuínas das espúrias e (ii) discernirmos a hierarquia dos vários tipos de necessidades genuínas. Se esse padrão existir e puder ser conhecido, falaríamos em direito natural; caso contrário, há tão-somente o direito positivo "determinado exclusivamente pelos legisladores e pelos tribunais dos diversos países" 31 . É justamente por rejeitar as pretensões (i) e (ii) que a ciência social moderna e o historicismo contestam a possibilidade mesma da filosofia política. Por que a ciência social moderna rejeita a possibilidade da filosofia política? Em sentido geral, a ciência social moderna designa a investigação das coisas políticas guiada pelo modelo da ciência da natureza ${ }^{32}$. Inicialmente, essa ciência social "positiva", tal como elaborada por Augusto Comte, esperava "superar a anarquia intelectual da sociedade moderna" pela supressão das "vãs e estéreis especulações" da filosofia política em prol do estudo experimental e empírico ${ }^{33}$. A moderna ciência da natureza, diferente da antiga filosofia da natureza, possui uma concepção não-teleológica do universo, ou seja, recusa que "todos os seres naturais têm um fim natural, um destino natural, que determina quais são as operações boas para eles" ${ }^{\prime 3}$. Assim, décadas depois, a ciência social positivista abandona a também vã e estéril esperança de superar a anarquia intelectual da sociedade moderna, ao perceber que tal objetivo pressupõe uma ideia de melhor e de pior incompatível com o estudo experimental e empírico. Estabelece assim uma disjunção entre fatos e valores, determinando que apenas aqueles poderiam ser objeto de investigação científica ${ }^{35}$. Afinal, como daquilo que é não se pode deduzir o que deve-ser, o cientista social precisa então ser "isento de valores" ou "eticamente neutro" ${ }^{36}$. Ser eticamente neutro consiste em abdicar de qualquer julgamento em relação aos conflitos entre o bem e o mal, inclusive acerca de como o bem e o mal devam ser entendidos ${ }^{37}$. A ciência social condena como a-científico um estudo sobre o que é bom, da boa vida, da melhor sociedade, de como deve o homem viver; i.e, nega não só a existência, mas a possibilidade mesma de uma

\footnotetext{
${ }^{30}$ Ibidem, p. 78-80.

31 Ibidem, prefácio.

32 STRAUSS, L. What is Political Philosophy?, p. 13.

33 Ibidem, p. 18.

34 STRAUSS, L. Direito Natural e História, p. 8-9.

35 STRAUSS, L. What is Political Philosophy?, p. 18.

36 STRAUSS, L. Direito Natural e História, p. 38.

${ }^{37}$ STRAUSS, L. What is Political Philosophy?, p. 18.
} 
filosofia política. Disso Strauss conclui que a "obtusidade moral" é a exigência necessária para a investigação científica moderna e, por isso, "quanto mais sérios cientistas sociais nós nos tornemos, quanto mais desenvolvermos um estado de indiferença em relação a qualquer objetivo geral, mais estaremos diante de um estado de despropósito e desalento que se poderia denominar de niilismo"38.

Todavia, será a investigação do cientista social moderno isenta de valores? A ciência social positivista, analisa Strauss, espera "se contrapor à perigosa influência das preferências pessoais pela dedicação a apenas um único valor: a verdade" 39 . Justamente por seguir o caminho adequado para alcançar a verdade é que a ciência se distingue e rejeita as vãs e estéreis especulações dos filósofos políticos. Entretanto, o cientista isento de valores e eticamente neutro não está autorizado, em seus próprios termos, a escolher racionalmente a busca pela verdade como mais valiosa do que a inverdade ou mesmo a ignorância. Se o faz, não apenas a ciência social, mas a própria ciência se guia por uma escolha subjetiva e, portanto, "a-científica". O cientista social tenta justificar a necessidade da busca pela verdade e, por conseguinte, da relevância da ciência social, pela proposição de que sua tarefa é indicar objetivamente os meios adequados para que possamos alcançar os fins que desejamos - sejam estes quais forem. Se uma ciência social cuja busca pela verdade nos permita obter os meios adequados para realizar nossos fins for preferível em si mesma a qualquer outra disciplina que não ofereça tais benefícios, cabe, com Strauss, questionar se o reconhecimento da existência de um valor racionalmente preferível em relação aos demais não nos justificaria a suspeitar da possibilidade de que outros valores disponham do mesmo estatuto. Caso o cientista social contra-argumente que antes acredita do que sabe que a verdade é um "bem", estamos novamente sujeitos a tanto aceitar quanto repudiar a busca pela verdade e a ciência social. Por tal recusa em refletir acerca dos fins, embora os assumindo como valores a serem alcançados, Strauss sentencia que "a suposta 'neutralidade ética' do cientista social [...] alimenta menos o niilismo do que o conformismo e o filisteísmo". Dito de outro modo: a despeito de ser um niilista teórico, o cientista social é, na prática, apenas um conformista negligente ${ }^{40}$. Porém, a dificuldade ou mesmo incapacidade da ciência social em se manter eticamente neutra seria o sintoma da fragilidade teórica da própria ciência social positiva ou apenas uma limitação dos atuais cientistas? Tal questão conduz Strauss a examinar se realmente é possível estudar os fenômenos sociais "i.e., todos os fenômenos socialmente relevantes, sem que se façam julgamentos de valor" 41 .

\footnotetext{
38 Ibidem, p. 18-19.

39 Ibidem, p. 19.

${ }^{40}$ Ibidem, 19-20.

41 Ibidem, p. 20-21
} 
Para examinar esse ponto central, Strauss recorre oportunamente ao pensamento do "maior cientista social de nosso século", Max Weber ${ }^{42}$. Embora jamais tenha explicado o que entendia por "valores", Weber estabeleceu que "os objetos da ciência social são constituídos por referência a valores", porquanto "sem esta referência não haveria concentração em interesses específicos, nem uma seleção razoável dos temas, nem princípios de distinção entre fatos relevantes e irrelevantes" ${ }^{\prime 3}$. Não obstante a referência a valores seja imprescindível à ciência social, argumenta Weber, há uma assimetria fundamental entre "referência a valores" e "juízos de valor"; afinal, "ao dizer que algo é relevante para a liberdade política, nem por isso se toma uma posição a favor ou contra a liberdade política" "44. Nesse sentido, o cientista social que constata que as pessoas desejam realizar os seus fins e se dispõe a indicar os meios apropriados para tanto estaria simplesmente fazendo referência aos valores da comunidade e não ajuizando racionalmente que estes são bons ou ruins em si mesmos. A despeito de a ciência social positiva não poder sequer discernir o que é e o que não é "político" sem referência aos propósitos e aspirações de uma sociedade, tal referência não implica, em princípio, a aceitação ou não desses propósitos e aspirações ${ }^{45}$. Eticamente neutra é a ciência social que evita juízos de valor e não a que esteja isenta de referência a valores. Para Strauss, "Weber afirmava que a sua ideia de uma ciência social isenta de valores ou eticamente neutra é inteiramente justificada por aquilo que ele considerava a mais fundamental de todas as oposições, designadamente a oposição entre o ser e o dever-ser" ${ }^{36}$. Como dito, não se pode derivar daquilo que é aquilo que deve ser; dado que a ciência, experimental e empírica, apenas tem acesso ao que é (fatos), então esta não é apta a se pronunciar sobre aquilo que deve ser (valores). Apesar disso, assegura corretamente Strauss, a mera heterogeneidade entre fatos e valores não justifica que a ciência social não possa se pronunciar sobre aquilo que deve ser, pois, se não podemos determinar o que deve ser a partir daquilo que é, por outro lado, poderíamos guiar aquilo que é pelo que deve-ser. Ao afirmar que a ciência social apenas pode investigar aquilo que é, assume-se tacitamente que não se pode conhecer racionalmente o que deve ser, i.e., que os "conflitos entre diferentes valores ou sistemas de valor são essencialmente insolúveis para a razão humana" ${ }^{47}$. Não é a heterogeneidade entre ser e dever-ser o que conduz à suposta impossibilidade de se realizar julgamentos de valor, mas a incapacidade da

\footnotetext{
42 STRAUSS, L. Direto Natural e História, p. 34.

${ }^{43}$ Ibidem, p. 35.

${ }^{44}$ Ibidem, p. 37.

${ }^{45}$ STRAUSS, L. What is Political Philosophy?, p. 22.

${ }^{46}$ STRAUSS, L. Direito Natural e História, p. 38.

${ }^{47}$ STRAUSS, L. What is Political Philosophy?, p. 22.
} 
razão "entregue a si mesma" em solucionar todo e qualquer conflito de valores. Essa hipótese de leitura se justifica especialmente quando Weber, numa das poucas ocasiões em que discute exemplos dos supostos conflitos insolúveis entre valores, permite inferir que não temos como decidir racionalmente entre uma ética intramundana e uma ética supramundana. Mais precisamente: Weber está convencido de que uma orientação ética estritamente intramundana não poderia nos assegurar "normas absolutamente válidas", sendo que estas apenas poderiam ser obtidas por uma ética supramundana (fundada na revelação); ora, como a ciência social investiga somente o que diz respeito ao intramundano, os conflitos de valores permaneceriam insolúveis (assim como a disputa a propósito de qual dessas éticas é legítima $)^{48}$. Entretanto, contesta Strauss, se talvez não possamos decidir racionalmente entre uma ética intramundana e outra supramundana, a assertiva de que uma ética intramundana é incapaz de alcançar normas absolutamente válidas, "embora seja tomada como suficientemente estabelecida, jamais foi provada"49. Afinal, "Weber nunca demonstrou que a razão humana entregue a si mesma é incapaz de chegar a normas objetivas ou que é impotente para resolver o conflito entre diferentes doutrinas éticas intramundanas" 50 . Para tanto, seria necessário "algo como uma coerente crítica da razão avaliativa", até aqui não realizada ou sequer esboçada adequadamente. A suposta impossibilidade de se decidir racionalmente acerca de conflitos de valor advém simplesmente de "observações esparsas que pretendem provar que este ou aquele específico conflito de valor específico é insolúvel"51. Desse modo, é legítimo suspeitar de que provavelmente haja conflitos de valor insolúveis pela razão humana; porém, de que haja conflitos insolúveis não se segue que todas as disputas racionais sobre valores sejam insolúveis ou mesmo que algumas das disputas mais urgentes não possam ser solucionadas ("Se não podemos decidir qual dentre duas nações que estão em guerra há séculos tem a causa mais justa isso significa que também não podemos decidir que a ação de Jezebel contra Nabo foi imperdoável?") ${ }^{52}$.

Parte significativa do segundo capítulo de Direito Natural e História é dedicada à análise cuidadosa da obra de Weber para mostrar como ele próprio, tal como a maioria dos cientistas sociais modernos, não se isenta de fazer julgamentos de valor. No entanto, uma retomada em pormenor desse debate extrapolaria os objetivos deste ensaio, além de que talvez seja desnecessária caso se concorde

\footnotetext{
${ }^{48}$ STRAUSS, L. Direito Natural e História, p. 61-61.

${ }^{49}$ Ibidem.

${ }^{50}$ STRAUSS, L. Direito Natural e História, p. 62

${ }^{51}$ STRAUSS, L. What is Political Philosophy?, p. 23.

52 Ibidem.
} 
que a tese sobre a impossibilidade de decidirmos racionalmente sobre todos os conflitos de valor é excessiva e, até o momento, injustificada. Se é correto que, em si mesma, "a tese de Weber conduz necessariamente ao nïlismo, ou seja, à ideia de que cada preferência, por má, vil ou insana que seja, tem de ser julgada pelo tribunal da razão como sendo tão legítima como qualquer outra" 53 , uma vez que o próprio Weber não conseguiu ser eticamente neutro, ele não seria um niilista e sim, como a maioria dos cientistas sociais, um conformista ou filisteu da cultura ${ }^{54}$.

O verdadeiro antagonismo quanto à possibilidade da filosofia política se mostra naqueles cientistas sociais que, coerentes com suas premissas, são levados a questionar a sua busca pela verdade e, por conseguinte, a própria noção de "ciência". Isto se dá quando esses cientistas, temerosos de evitar que suas asserções sejam apenas projeções de opiniões de seu próprio tempo, lançam-se em investigações sobre outras culturas e épocas. Todavia, como em tal empreita eles fazem uso de um esquema conceptual de sua própria época e cultura, eles tentam evitar novamente o anacronismo ou etnocentrismo ao almejarem entender essas outras culturas como elas entenderam a si mesmas. Não obstante a ciência social empregue os recursos da lógica para realizar suas investigações, as perguntas das quais parte são fundamentalmente subjetivas (advindas dos interesses desta ou daquela cultura e época). Logo, torna-se problemático para essa forma de ciência social distinguir rigorosamente entre objetivo e subjetivo. Como os cientistas sociais modernos não quiseram recair num platonismo que propõe valores intemporais subjacentes ao mundo, concluíram que "os valores de uma dada ciência social dependem da sociedade a qual esta ciência social pertence, ou seja, da história". Em consequência disso, a ciência social moderna passa a ver a si mesma como um modo historicamente relativo de compreender as coisas que em princípio não é nem superior nem inferior a modelos de compreensão alternativos. Esse entendimento ou "consciência histórica" se torna assim a base de uma ciência social não mais positivista, mas "historicista". "É apenas

\footnotetext{
53 STRAUSS, L. Direito Natural e História, p. 39.

${ }^{54}$ Ibidem, p. 33-39; 62; 68-70. Apesar de suas críticas ao estudo científico da política, como faz ver Nasser Behnegar, em seu Leo Strauss, Max Weber and the Scientific Study of Politics, p. 1, "Leo Strauss is a friend, perharps an indispensable friend, of the scientific study of politics. This is not to say that the impression to the contrary fostered by Strauss's polemic against the scientific study of politics is altogether misleading, for he does deny that political science can be actualized without a radical rejection of the contemporary scientific approach to the study of politics. But unlike the critics of that approach who maintain that 'no science of politic is possible; or, if possible, desirable (Charles Beard, quoted in Easton, 1953), Strauss objection to modern social science not because it insist on precision but because it is not precise regarding the most important issues. [...] Strauss turned away from the 'value-free' social science of his time, which could not understand Hitler's and Stalin's regimes as tyrannies, and turned toward classical political philosophy out of a desire for a genuine social science".
} 
neste ponto", revela Strauss, "que nos colocamos face a face com o principal antagonista da filosofia política: o historicismo"

$\mathrm{O}$ "ataque ao direito natural em nome da história" se inicia com a afirmação de que aquele se quer discernível pela razão humana e universalmente válido; mas a história (e a antropologia) mostram que um tal direito não existe, pois encontramos nas sociedades diversas noções de direito ou de justiça ${ }^{56}$. Em primeiro lugar, os maiores "professores" de direito natural ensinam que, precisamente por ser racional, o encontro deste pressupõe o cultivo da razão e, por isso, não pode ser, em princípio, universalmente conhecido. Em segundo lugar, a diversidade de concepções de justiça, longe de ser incompatível com a ideia de direito natural, é sua própria condição. Afinal, se houvesse um consenso universal entre todas as comunidades quanto às leis não teríamos motivos para questioná-lo. É por haver discrepâncias que nos colocamos a interrogar qual dos códigos sociais disponíveis é o melhor ou se há um código superior. Daí porque a "descoberta" da diversidade de opiniões quanto ao direito e à justiça não é moderna e constitui inclusive o ponto de partida da filosofia política clássica. Contudo, há uma profunda diferença entre os antagonistas dos primeiros filósofos políticos - os que originalmente afirmavam o caráter convencional de todo o direito - e os partidários da perspectiva história moderna. Enquanto os convencionalistas clássicos também assumiam a distinção entre natureza e convenção como fundamental e concediam àquela "uma dignidade incomparavelmente superior ao decreto da sociedade", os partidários da perspectiva histórica ou bem recusam como mítica tal separação ou, quando a admitem, não tomam a natureza como "a norma", atribuindo ao mundo e à criatividade humana um estatuto superior. Logo, diferente do convencionalismo clássico, a escola histórica rejeita o ponto de partida da filosofia política. O que torna para Strauss a

\footnotetext{
55 STRAUSS, L. "What is Political Philosophy", p. 25-26.

${ }^{56}$ STRAUSS, L. Direito Natural e História, p. 11. No capítulo 3 de seu Nova Luz sobre a Antropologia, intitulado "Anti anti-relativismo", Clifford Geertz propõe: "não quero defender o relativismo, grito de guerra do passado e afinal uma palavra desgastada, mas atacar o anti-relativismo, que me parece estar em ampla ascensão e representar uma versão aerodinâmica de um erro antigo. [...] Como notou o filósofo e antropólogo John Ladd, 'todas as definições comuns do ... relativismo são formuladas por adversários do relativismo ... e são definições absolutistas. [...] E, como também afirma Ladd, o resultado disso é que é que o relativismo ou qualquer coisa que se pareça com ele segundo essas definições hostis é identificado com o niilismo. Sugerir que talvez não existam fundamentos 'sólidos' para os juízos cognitivos, estéticos ou morais, ou, pelo menos, que são duvidosos aqueles que nos são oferecidos, é ver-se acusado de descrer da existência do mundo físico, de achar que as trivialidades são tão boas quanto a poesia, de ver Hitler apenas como um sujeito de gostos pouco convencionais ou até, como me aconteceu recentemente, de não ter "nenhuma posição política"' [p. 47-48]. Uma vez que Strauss é um adversário tanto do "absolutismo" quanto do relativismo, sendo que inclusive os excessos daquele lhe parecem ter contribuído para a ascensão deste [cf. Direito Natural e História, p. 22], tem-se no debate com a antropologia, ao estilo de Geertz, um contraponto para pôr à prova o antirrelativismo de Strauss.
} 
disputa com o historicismo ainda mais relevante é que a gênese da escola histórica não se deu no campo da filosofia em geral, porém, no âmbito da própria filosofia política, mais precisamente, como uma crítica à doutrina do direito natural do século XVIII. Dito diretamente: “o historicismo é o resultado final da crise do direito natural moderno" $" 57$.

Recuperando a gênese da escola histórica, Strauss indica que o historicismo apareceu no século XIX, especialmente como uma "reação à Revolução francesa e às doutrinas do direito natural" a ela relacionadas. "Os fundadores da escola histórica haviam compreendido que a aceitação de princípios universais ou abstratos gera necessariamente um efeito revolucionário, perturbador e desestabilizante", uma vez que, "com o reconhecimento de princípios universais o homem é forçado a julgar a ordem estabelecida [...] à luz da ordem natural ou racional" e, assim, "o que é real aqui e agora" parece sempre estar "aquém da norma imutável e universal". Por sua vez, a visada dos revolucionários era contra "todas as formas de supermundanidade ou de transcendência" e, por isso, defendiam uma versão do direito natural segundo a qual "o natural é sempre individual". Os criadores da escola histórica radicalizaram essa posição, ao concluírem que mesmo um direito natural que é sempre individual ainda permanecia vinculado ao que está além do aqui e do agora. Curiosamente, os conservadores sequer perceberam que ao rejeitarem o suposto direito natural de cada indivíduo para perseguir como desejar a sua própria versão de felicidade estavam antes consolidando a tendência teórica de seus adversários. Afinal, o resultado da crítica historicista à ideia de que "O direito natural é sempre individual" é uma supressão até ali inaudita de todas as formas de supermundanidade e transcendência. Em face disso, o que esse primeiro momento da escola histórica "proclamava ser universal aparecia como decorrente de algo que estava confinado ao local e ao temporal, como o local e o temporal in statu evanescendi". Daí por que, "ao tentar descobrir padrões que fossem simultaneamente objetivos e relativos a situações históricas particulares, a escola histórica atribuiu aos estudos históricos uma importância muito superior à que alguma vez haviam tido". Desse modo, o historicismo não se confunde com a história e sim constitui uma determinada concepção e valoração da história, cujo passo decisivo não foi "a descoberta da diversidade local e temporal das ideias de justiça - o óbvio não tem de ser descoberto", mas a crença na superioridade do local e do temporal sobre o universal ${ }^{58}$.

Dessas posições iniciais surge o primeiro momento da escola histórica, denominado por Strauss de "teórico", que procurava então obter uma objetividade

\footnotetext{
57 STRAUSS, L. Direito Natural e História, p. 4-5; 11-14; 32.

58 STRAUSS, L. Direito Natural e História, p. 14-17.
} 
restrita e momentânea pela suposta existência e eventual combinação de "um espírito popular" com "leis gerais da evolução histórica”. Em seguida, quando o historicismo se associa a "uma forma particular de positivismo [...] que sustentava que a teologia e a metafísica haviam sido suplantadas pela ciência positiva e assim identificava o conhecimento genuíno da realidade com aquele gerado pelas ciências empíricas", aqueles pressupostos transempíricos gradativamente foram abandonados. Após desacreditar os princípios universais ou abstratos, a escola histórica apostou que suas pesquisas empíricas seriam capazes de revelar "a existência de padrões particulares ou concretos". Infelizmente, como "os únicos padrões que restavam tinham um caráter meramente subjetivo e nenhum outro suporte além da livre escolha do indivíduo", o historiador criterioso e imparcial foi levado a admitir "a sua incapacidade para deduzir normas a partir da história, uma vez que não restavam quaisquer normas objetivas". Como os clássicos consideravam que não havia um sentido no processo histórico ou talvez nem houvesse algo como um "processo histórico", Strauss faz ver que uma primeira alternativa aos obstáculos encontrados pela escola história teria sido um retorno à perspectiva pré-historicista. Entretanto, "a disposição criada pelo historicismo e pelo seu fracasso prático foi interpretada como a inédita experiência da verdadeira [e até então oculta] situação do homem enquanto homem" e, como dali em diante não havia mais quaisquer normas objetivas e "nenhum critério objetivo permitia a distinção entre boas e más escolhas", deu-se o abandono de todos os critérios racionais e/ou filosóficos de avaliação, de sorte que "o historicismo culminava no nïlismo". Esse segundo momento é designado como um "historicismo radical" ou "existencialista" e Strauss o situa, se não em Nietzsche, ao menos nos seus "sucessores" - dos quais o último Heidegger é o ponto culminante. A tese fundamental do historicismo existencialista é de que "toda compreensão e todo conhecimento, por mais limitado e científico que possa ser, pressupõe um enquadramento de referência; pressupõe um horizonte, uma visão englobante sem a qual não é possível conhecer". Essa visão englobante, por ser a base de todo e qualquer raciocínio, "não pode ser validada por um raciocínio"; ora, como "há uma diversidade de visões englobantes e cada uma delas é tão legítima quanto a outra, temos de escolher algumas destas sem qualquer orientação racional". Dessa maneira, o historicismo radical ou existencialista, "ao negar o significado, se não a existência, de normas universais, destruiu a única base sólida de todos os esforços sérios para transcender o atual" "59. Visto que a escola histórica é bem mais do que

\footnotetext{
59 Ibidem, p. 18-31. Quando Strauss discute a "solução" moderna ao problema da filosofia política, após estabelecer os dois primeiros momentos em torno de nomes como Maquiavel e Rousseau, afirma: "The difficulties to which German idealism was exposed gave rise to the third wave of modernity - of the wave that bears us today. This last epoch was inaugurated by Nietzsche". Não surpreende assim que, como recupera L. Lampert, Strauss declara em sua correspondência com Karl Löwith que, "entre
} 
uma orientação filosófica dentre outras, "porém a mais poderosa força que afeta ao pensamento atual, sendo que, na medida em que podemos falar de um espírito de nosso tempo, podemos afirmar que este seria o historicismo" ${ }^{60}$, justifica-se por que, sob sua vigência, não há sequer a possibilidade da filosofia política. A rejeição do direito natural em nome da história nos conduz ao niilismo e, por sua vez, o niilismo impede a mencionada busca por um padrão que nos permita decidir entre as necessidades genuínas e as espúrias, e discernir a hierarquia dos vários tipos de necessidades genuínas.

No entanto, seria apropriada a recusa do direito natural e da filosofia política em nome da história? Em primeiro lugar, como mencionado, é um equívoco considerar que o direito natural requer um consenso universal, pois pressupõe o cultivo da razão e assim "entre os selvagens não se deve esperar nenhum conhecimento real do direito natural". Por isso, como professaram Sócrates e Platão, basta que tal consenso seja potencial e, quem sabe, discernível pela ascensão das opiniões a "uma verdade autossubsistente que cada homem nunca deixa de pressentir". Como a crítica historicista não se trata de uma negação daquilo que acontece, mas da possibilidade de que algo possa acontecer, Strauss entende que "a rejeição contemporânea do direito natural baseia-se não em evidência histórica, mas numa crítica filosófica da possibilidade ou cognoscibilidade do direito natural". Destaque-se que essa crítica é bastante distinta da empreendida pelos céticos, pois, se para estes "todas as afirmações são incertas e, portanto, essencialmente arbitrárias", por sua vez, aquela acredita que "as afirmações que

meus 22 e 30 anos, Nietzsche me dominava e encantava de tal maneira que eu literalmente acreditava em tudo o que ele dizia" [apud LAMPERT, L. Strauss and Nieţsche, p. 5]. Um balanço crítico sobre o embate de Strauss com o historicismo existencialista está em Stanley Rosen, Leo Strauss and the Problem of Modern.

${ }^{60}$ STRAUSS, L. Political Philosophy and History [In: What is Political Philosophy and Others Writings, p. 56-58]. Daí que, polemicamente, Strauss afirma que "a filosofia política não é uma disciplina história", pois "as questões filosóficas sobre a natureza das coisas políticas e a melhor ou mais justa ordenação social são fundamentalmente diferentes de questões históricas, as quais concernem tão-só ao que é individual". A filosofia política diz respeito ao que persiste, embora não se restrinja a este ou aquele sujeito, grupo ou civilização; daí que é essencialmente distinta da própria história da filosofia política, já que "a questão da natureza das coisas políticas e sua resposta não pode ser confundida com a pergunta por como este ou mesmo todos os filósofos abordaram, discutiram ou responderam a tal problema". Assim, "a forma mais comum de historicismo demanda que as perguntas pela natureza das coisas políticas, do estado, da natureza do homem, dentre outras", que interessam à filosofia política, devam ser substituídas por indagações sobre o estado moderno, o governo moderno, o homem moderno, a atual situação política, nossa sociedade, nossa civilização, etc.”. Se isso não quer dizer que a história seja irrelevante, porque é justamente a experiência da diversidade de instituições e modos nos diferentes países e épocas que impulsiona a interrogação pela existência ou não da melhor ou mais justa ordenação política, "a história, contudo, é importante à filosofia política apenas de maneira preliminar ou auxiliar" [ibidem]. 
prevalecem em diferentes épocas e em diferentes civilizações estão muito longe de serem arbitrárias", já que se reconhece, "dentro de certos limites, a possibilidade de um conhecimento genuíno" ${ }^{61}$. O historicismo estaria justificado em reconhecer para si um conhecimento genuíno? Como o historicismo afirma que todos os pensamentos humanos são transitórios, e o próprio historicismo é também um pensamento humano, segue-se que este "só pode ter uma validade temporária, o que vale por dizer que não é pura e simplesmente verdadeiro". Caso se venha a assumir que "o pensamento que reconhece a relatividade de todas as concepções englobantes tem um caráter diferente do pensamento que está sob o domínio de uma concepção englobante", o historicismo se admitiria como "uma conclusão teorética que transcende a história" e, assim, novamente refutaria a si mesmo. Uma tentativa de superar essas dificuldades está na presunção de que "não é preciso transcender a história para ver o caráter histórico de todo pensamento: há um momento privilegiado, um momento absoluto no processo histórico em que o caráter essencial de todo o pensamento se torna autotransparente". Tal é a posição do primeiro movimento ("teórico") do historicismo e, por isso, "Hegel ensinara que todas as filosofias são a expressão conceptual do espírito das suas respectivas épocas e, todavia, garantia a verdade absoluta de seu próprio sistema filosófico". Convencido - e com bons motivos para tanto - de que as posições teóricas dos primeiros historicistas pressupunham noções metafísicas e/ou transistóricas, o segundo movimento ("radical" ou existencialista") do historicismo enfatizou que o instante privilegiado se dá quando "da negação da metafísica teorética e de uma ética filosófica ou do direito natural" e, por conseguinte, pelo reconhecimento da impossibilidade "de se resolverem os enigmas fundamentais". A "consciência histórica" da impossibilidade de se resolverem os enigmas fundamentais seria um conhecimento genuíno por significar a mencionada experiência inédita da verdadeira situação do homem enquanto homem. Ora, "ao afirmar que todo o pensamento humano ou pelo menos que todo o pensamento humano relevante é [tão-somente] histórico, o historicismo [existencialista] admite que o pensamento é capaz de chegar a uma conclusão importantíssima que é universalmente válida e que não será de forma alguma afetada por quaisquer surpresas futuras". Assim, o historicismo existencialista é reconduzido à universalidade [e ao direito natural] que busca refutar ou ao paradoxo inicial de como um pensamento que defende a radical historicidade de todos os pensamentos pode, ele mesmo, ser transistórico ${ }^{62}$.

A suspeita de Strauss é de que, principalmente na transição do historicismo teórico para o existencialista, "a experiência histórica nunca foi sujeita a uma análise crítica", já que sequer "se levantou a questão de saber se esta experiência

\footnotetext{
61 STRAUSS, L. Direito Natural e História, p. 11-14; 20-23; 24.

62 STRAUSS, L. Direito Natural e História, p. 11-14; 20-23; 24-25.
} 
poderia receber uma interpretação completamente diferente e talvez mais adequada", o que, se correto, confirmaria a acusação de que "o historicismo é o disfarce que nos nossos dias o dogmatismo gosta de usar". Note-se que, caso o "momento privilegiado" do historicismo existencialista esteja correto, não se seguiria do caráter irresolúvel de todos os enigmas o abandono da filosofia e sim a substituição de "uma filosofia não-historicista e dogmática por uma filosofia não-historicista e cética". Diante disso, a possibilidade da filosofia política tem de ser decidida entre uma concepção historicista e uma não-historicista e "como esta não será compreendida se for vista apenas do modo como se apresenta a si mesma do ponto de vista do historicismo", é central para Strauss que "o problema do historicismo tem de ser considerado do ponto de vista da filosofia clássica, que constitui o pensamento não-historicista na sua forma pura" ${ }^{\text {"3 }}$. Restaurar o ponto de vista não-historicista da filosofia clássica, para discutir criticamente o espírito de nossa época, exige uma interpretação não-historicista da filosofia política e, talvez por isso, genuinamente histórica. Não é outro senão este o percurso reconstituído até aqui quanto ao procedimento metódico de Strauss. É no sentido de uma abordagem não-historicista da filosofia que se pode reclamar o renascimento do racionalismo político clássico.

Se, contra a tese historicista, a permanência das mesmas questões fundamentais, a despeito de poderem ou não ser solucionadas, é suficiente para mostrar que a filosofia é possível, já a existência do direito natural depende de se o problema fundamental da filosofia política pode ser resolvido de maneira definitiva. Esse problema, para um discípulo de Sócrates como Strauss, remete a se podemos responder "à pergunta de como deve o homem viver", interrogação que se torna patente, quando "tomamos consciência da nossa ignorância das coisas mais importantes". Se, diante do predomínio atual do historicismo, a filosofia política precisa antes de tudo justificar a sua possibilidade mesma, entende-se por que Strauss julga que seu retorno ao pensamento político clássico nada tem a ver com um desejo romântico de autoesquecimento ou uma busca desinteressada pelo conhecimento, mas sim como uma tentativa de pensar "a crise de nosso tempo" ${ }^{64}$. E, igualmente, mostra-se assim o ponto de partida indispensável para quem se dispuser a pensar hoje a questão do político.

\footnotetext{
${ }^{63}$ Ibidem, p. 28-29; 31; 109.

${ }^{64}$ STRAUSS, L. The City and Man, p. 1.
} 
SAMPAIO, Evaldo. Nihilism and politics in Leo Straus. Trans/Form/Ação, Marília, v. 35, n. 1, p. 135-136, Jan./Abril, 2012.

\begin{abstract}
The aim of this article is to think about the possibility of political philosophy, taking Leo Strauss's work as a point of departure. It examines why contemporary nihilism - in its most widespread and sometimes hidden personifications - prevents the achievement, and even the existence, of a reflection on the nature of political things. Assuming that Strauss's reflections on "natural right" are as much the key to understanding "the central problem of political philosophy" as to confronting Strauss's principal opponents, this article analyzes the meaning and the plausibility of Strauss's critique of the motives that lead us to nihilism and, if these prove to be appropriate, to indicate how a "rebirth of classical political philosophy" could reconduct us to a philosophical meditation on the good life, what is good, the best society, and "how man must live".
\end{abstract}

KEYWORDS: natural right, nihilism, L. Strauss

\title{
REFERÊNCIAS
}

BEHNEGAR, N. Leo Strauss, Max Weber and the Scientific Study of Politics. Chicago: Chicago University Press, 2003.

GEERTZ, C. Nova Lu₹ sobre a Antropologia. Rio de Janeiro: Jorge Zahar, 2001.

JANSSENS, D. Between Jerusalem and Athens: Philosophy, Prophecy and Politics in Leo Strauss's Early Thought. Albany, NY: Suny Press, 2008.

KRAMER, J. "To Spare the Vanquished and Crush the Arrogant": Leo Strauss's Lecture on "German Nihilism". In: SMITH, S. (Ed.). The Cambridge Companion to Leo Strauss. Cambridge: Cambridge University Press, 2009, p. 171-192.

LAMPERT, L. Leo Strauss and Nietzsche. Chicago: Chicago University Press, 1996.

MEIER, H. Strauss and the Theologico-Political Problem. Cambridge: Cambridge University Press, 2006.

NORTON, A. Leo Strauss and the Politics of American Empire. Yale: Yale University Press, 2005.

ORR, S. Jerusalem and Athens: Reason and Revelation in the Works of Leo Strauss. Lanham, MD: Rowman \& Littlefield, 1995.

PANGLE, T. Leo Strauss: An Introduction to his Thought and Intellectual Legacy. Baltimore: Johns Hopkins University Press, 2006.

ROSEN, S. Leo Strauss and the Problem of Modern. In: SMITH, S. (Ed.). The Cambridge Companion to Leo Strauss. Cambridge: Cambridge University Press, 2009, p. 119-136. 
SMITH, S. Leo Strauss Today. In: (Ed.). The Cambridge Companion to Leo Strauss. Chicago: Chicago University Press, 2009, p. 1-12.

STRAUSS, L. The City and the Man. Chicago: University of Chicago Press, 1964. . Direito Natural e História. Lisboa: Edições 70, 2009. . Natural Right and History. Chicago: University of Chicago Press, 1999. ; SEDEYN, O. Nibilisme et Politique. Paris: Rivages Poche, 2004. ; PANGLE, T. (Org.). The Rebirth of Classical Political Rationalism. Chicago: University of Chicago Press, 1989. Press, 1959. What is Political Philosophy? (and Other Studies). Chicago: University of Chicago TANGUAY, D. Leo Strauss: An Intellectual Biography. New Haven: Yale University Press, 2007.

ZUCKERT, C.; ZUCKERT, M. The Truth about Leo Strauss: Political Philosophy and the American Democracy. Chicago: Chicago University Press, 2006.

ZUCKERT, M. Straussians. In: SMITH, S. (Ed.). The Cambridge Companion to Leo Strauss. Chicago: Chicago University Press, 2009, p. 263-286.

Recebido em: 21.09.2011

Aprovado em: 16.11.2011 